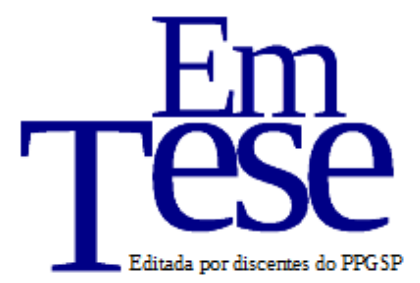

UFSC

PPG SP PROG RAMA DE

PÓS-GRADUAÇÃO EM

Sociologia

Política

v. 12, n. 2, ago./dez., 2015

\title{
O conceito de classe: os livros didáticos de sociologia e a proposta de E.P. Thompson
}

\author{
Kênia Mara Gaedtke ${ }^{1}$ \\ A classe é definida pelos homens \\ enquanto vivem sua própria história e, \\ ao final, esta é sua única definição.
}

(THOMPSON, 2004)

\section{Introdução}

O avanço da consolidação da sociologia como componente curricular em todas as escolas de Ensino Médio no Brasil tem transformado a forma como essa ciência é vista no país. Os livros didáticos são, nesse contexto, um mediador importante no processo de ensino e aprendizagem, trazendo consigo os referenciais teórico-conceituais da disciplina e proporcionando uma conexão entre o/a professor/a, estudantes e o conhecimento sociológico.

No ano de 2014 foram apresentados aos/às docentes da área, seis livros didáticos de sociologia aprovados através da segunda edição do Programa Nacional do livro Didático - PNLD, para avaliação e escolha de qual desses instrumentos será incorporado nas aulas na escola em que atuam. Serão, a partir do ano letivo de 2015, cerca de oito milhões de estudantes de escolas públicas em todo o país que terão acesso a esse material (Guia PNLD, 2014).

É fundamental que a avaliação destes materiais, por parte do/as docentes, esteja embasada numa especial atenção àquilo que é suprimido e àquilo que aparece no discurso do livro didático; e se aparece, de que forma isso se dá. Essa avaliação precisa

\footnotetext{
${ }^{1}$ Doutoranda no Programa de Pós-Graduação em Sociololgia Política da Universidade Federal de Santa Catarina (PPGSP/UFSC), professora do Instituto Federal de Santa Catarina (IFSC).
} 
levar em consideração o trato dado às teorias, aos temas e aos conceitos, e com o conceito de classe não seria diferente.

Quando se pensa na escolha do livro didático, é importante lembrar daquilo que nos fala Lajolo:

\begin{abstract}
Em sociedades como a brasileira, livros didáticos e não-didáticos são centrais na produção, circulação e apropriação de conhecimentos, sobretudo dos conhecimentos por cuja difusão a escola é responsável. Dentre a variedade de livros existentes, todos podem ter - e efetivamente têm — papel importante na escola. (LAJOLO 1996, p. 3).
\end{abstract}

Ainda segundo esta autora, é importante que os professores e professoras tenham clareza de que são, também eles, leitores e leitoras do livro didático, tanto quanto os alunos. Para ser considerado didático de fato, um livro precisa ser usado sistematicamente no processo de ensino-aprendizagem de um determinado ramo do conhecimento humano, geralmente organizado em uma disciplina consolidada, em forma de um aprendizado coletivo e mediado pelo(a) professor(a) (LAJOLO 1996, p. $4)$.

No caso específico da sociologia, diante de linhas acadêmicas que destoam tanto entre si em relação à classe - umas que enfatizam suas permanências e novas facetas, outras que vêm negando sua existência - quais caminhos foram tomados na construção dos livros didáticos de sociologia aprovados pelo Ministério da Educação? É esta a pergunta que irá guiar este trabalho, tendo como base teórica a noção de classe defendida por E.P. Thompson (2004).

O historiador inglês Edward Palmer Thompson (1924 - 1993) foi um pensador interessante e complexo, que tem sido constantemente revisitado não só em sua área, mas também nas ciências sociais como um todo. Sua contribuição pode ser observada nos estudos sobre a formação de classe e de movimentos sociais, valorizando na análise as vivências, aspirações e valores da classe trabalhadora ${ }^{2}$.

De acordo com Moraes e Müller (2012), a análise dos sujeitos envolvidos na construção dos seus próprios destinos é o foco principal dos estudos de Thompson, tendo relação direta com sua atuação política, que se opunha à desumanização crescente nas relações sociais.

\footnotetext{
${ }^{2}$ É importante lembrar que o uso da expressão classe trabalhadora é preferível em relação a operários ou classe operária, a despeito da tradução brasileira que opera com a expressão "classe operária".
} 
Para estes autores,

Thompson desenvolveu um importante diálogo entre as ciências sociais ao incorporar em suas pesquisas históricas categorias sociológicas, como também ao criticar as tendências funcionalistas de ambas as disciplinas, a Sociologia e a História. Nesse sentido, seu método para analisar a formação da classe trabalhadora pode ser visto como uma crítica às leis e regras metodológicas de historiadores sociais conservadores, de marxistas ortodoxos, bem como as dos sociólogos funcionalistas, responsáveis pelos "sistemas de estratificação", que pretendem explicar e justificar eventuais diferenças de classe. Thompson posicionou-se contra essas tendências enfatizando as relações entre o humano e o histórico. (MORAES e MÜLLER, 2012, p. 283-4, grifos dos autores).

Para tanto, este trabalho inicia buscando dar conta da ideia de classe defendida por Thompson, especialmente em "Formação da classe operária na Inglaterra" (publicado originalmente em 1963) e amparando-se em comentadores já consagrados, tais como Ellen Wood e outros. A partir daí, retoma as noções de classe apresentadas nos livros didáticos de sociologia e busca, ao final, comparar as noções de classe desses materiais didáticos com a proposta thompsoniana.

\section{A noção de classe em E.P. Thompson: aspectos primordiais}

Já na primeira página de seu prefácio, Thompson irá apresentar as bases para a sua compreensão do que é classe:

\footnotetext{
Um fenômeno histórico que unifica uma série de acontecimentos díspares e aparentemente desconectados, tanto na matéria-prima da experiência como na consciência. Ressalto que é um fenômeno histórico. Não vejo a classe como uma "estrutura", nem mesmo como uma "categoria", mas como algo que ocorre efetivamente (e cuja ocorrência pode ser demonstrada) nas relações humanas (THOMPSON, 2004, p. 9, grifo do autor).
}

Para Thompson, a classe precisa ser pensada como relação. A classe ocorre quando homens sentem e articulam a identidade de seus interesses entre si, contra outros homens cujos interesses diferem - e normalmente se opõem. Essas experiências de classe são determinadas, em grande parte, pelas relações de produção (THOMPSON, 2004).

É preciso compreender classe "como uma formação social e cultural, surgindo de processos que só podem ser estudados quando eles mesmos operam durante um 
considerável período histórico" (THOMPSON, 2004, p. 12). Classe é uma relação, não uma coisa. Não é um conceito estanque, mas está inserido num processo histórico de longo prazo.

Aqui, a classe é vista como algo que sempre se redesenha, mas não deixa de ser uma categoria analítica. A classe se transforma porque o real se transforma. A consciência de classe é, então, nesse contexto, "a forma como essas experiências são tratadas em termos culturais: encarnadas em tradições, sistemas de valores, ideias e formas institucionais. Se a experiência aparece como determinada, o mesmo não ocorre com a consciência de classe" (THOMPSON, 2004, p. 10).

O historiador irá chamar a atenção também para a leitura equivocada que se faz da noção de classe nos escritos de Marx:

\footnotetext{
Como a tosca noção de classe atribuída a Marx pode ser criticada sem dificuldades, assume-se que qualquer noção de classe é uma construção teórica pejorativa, imposta às evidências. Nega-se absolutamente a existência da classe. Sob outra forma, e por uma invasão curiosa, é possível passar de uma visão dinâmica para uma visão estática de classe. "Ela" - a classe operária - existe, e pode ser definida com alguma precisão como componente da estrutura social. (THOMPSON, 2004, p. 11)
}

$\mathrm{O}$ autor faz então uma crítica ao funcionalismo - mais especificamente à Ralf Dahrendorf, que, segundo Thompson, acaba promovendo uma cristalização da noção de classe. A consciência de classe acabaria sendo, nessa visão, algo daninho, inventado por intelectuais deslocados, impedindo a coexistência harmoniosa de grupos.

Alguns críticos afirmam que Thompson, ao trabalhar com uma noção pouco clara de classe, teria fundido classe com consciência de classe. Ellen Wood (2002) sai em defesa do autor e afirma que essas críticas estão baseadas em uma visão a-histórica do mundo. Para Wood, o argumento de Thompson tem força por indicar exatamente o contrário, ao ser capaz de reconhecer e explicar as operações de classe na ausência da consciência de classe, não negando as estruturas objetivas aí presentes.

A análise de classe de Thompson não é a clássica marxista, economicista. Ele não se restringiu aos números, mas atentou para outras questões da vida, visão que para alguns críticos foi vista como demasiadamente subjetiva. No entanto, a originalidade de sua interpretação sobre o tema vem sendo cada vez mais valorizada - Moraes e Müller, por exemplo, irão mostrar que 


\begin{abstract}
com vistas a identificar os aspectos humanos das relações de produção e a apreender a efetiva dimensão do antagonismo de classe, Thompson [..] julga útil, por exemplo, avaliar e comparar os conteúdos, os métodos e o significado de debates envolvendo noções como níveis salariais, padrão de vida, séries (históricas) de preços e seus resultados. Para ele, a medida da riqueza da classe trabalhadora da época não poderia ser julgada apenas em padrões quantitativos e, por esse motivo, considera que à visão reducionista escapam os aspectos qualitativos da vida da classe trabalhadora (MORAES e MÜLLER, 2012, p. 285).
\end{abstract}

Wood (2012) também mostra as contribuições dessa interpretação original de Thompson, que teria sido segundo a autora o único marxista que buscou compreender a classe em casos ambíguos. As condições objetivas levam a conflitos e lutas de classe formando a experiência, mesmo quando não há consciência de classe explicitamente visível - Thompson evidencia assim como os determinantes de classe formam os processos sociais.

A referência de classe puramente estrutural não observa as consequências práticas do processo social. A concepção de Thompson observa, nos diferentes contextos, como as formações de classe são resultado das diferentes situações objetivas, como a experiência comum e os interesses comuns formam a classe. Wood (2012) nos lembra ainda que em Thompson é possível visualizar a formação da classe na vivência das contradições das relações sociais de produção, nas experiências de determinadas situações, por isso a luta de classes precede a classe.

A noção de classe apresentada por Thompson (2004) está fortemente vinculada ao conjunto das suas teorias, o que é um fato importantíssimo, afinal, para o autor, a teoria tem implicações na prática. Como bem lembra Wood (2012), a sua definição de classe como processo ativo e relação histórica certamente foi formulada para defender a classe contra os que negam sua existência, além de ir de encontro às tradições intelectuais e às práticas políticas que suprimem a ação humana, e, mais especificamente a atividade inerente à classe trabalhadora no desenvolvimento histórico. Assim, Thompson buscou recobrar a "história que vem de baixo" como projeto político contra as opressões da dominação de classe e contra o programa de "socialismo visto de cima".

Passado mais de meio século da publicação de $A$ formação da classe operária inglesa (2004), muitos pesquisadores têm explorado as contribuições da obra na 
compreensão atual de classe. Rhomberg (2013), por exemplo, buscando apreender as contribuições metodológicas da obra, defende que a forma de representar a formação de classe escolhida por Thompson pode ser descrita como uma espécie de "biografia coletiva":

\begin{abstract}
en este sentido, las clases no son simples variables o, incluso, resultados, sino personajes de una trama, integrados en un argumento narrativo y desarrollados a través de la interacción con otros personajes o actores colectivos. El desarrollo de la conciencia o cultura de clase, por lo tanto, aparece como el retrato biográfico de un protagonista histórico, un Bildungsroman del desarrollo moral de un sujeto colectivo obrero. (RHOMBERG, 2013, p. 120).
\end{abstract}

Há outro aspecto importante da noção de classe em Thompson que Rhomberg recupera: Thompson sustenta que a formação da classe é um processo de lento, e completamente ligado às particularidades históricas e culturais de seu contexto.

Este decidido particularismo, concreción y compromiso con el lugar estudiado sirve para cimentar la imagen de unos trabajadores actuando como sujetos únicos, independientes, en la formación de sí mismos como clase. También acentúa la importancia de capturar las voces y experiencias perdidas del pobre tejedor, el aparcero ludita, el artesano utópico y otros, para afirmar su presencia en la historia y las realidades vividas de la clase. (RHOMBERG, 2013, p. 121).

Vê-se assim que a contribuição de Thompson para a compreensão da classe é ampla e frequentemente recuperada, inclusive na sociologia. Ao levar em consideração aspectos que foram minimizados ou até mesmo rechaçados por outros autores na análise da formação da classe, Thompson chama a atenção para a importância do contexto histórico, cultural e simbólico do fenômeno.

\title{
3. Livros didáticos de sociologia e classe
}

Para este trabalho, analisamos quatro dos seis livros didáticos de sociologia aprovados no PNLD de 2015³: Sociologia, da editora Scipione (ARAÚJO; BRIDI; MOTIM, 2013), a segunda edição de Tempos modernos, tempos de sociologia, da

\footnotetext{
${ }^{3}$ Os dois outros livros aprovados no programa (MACHADO, Igor J. R; AMORIM, Henrique; BARROS, Celso R. Sociologia hoje. São Paulo: Ática, 2013 e OLIVEIRA, Luiz F. e COSTA, Ricardo C. R. Sociologia para jovens do século XXI. $3^{\text {a }}$ Ed. São Paulo: Imperial Novo Milênio, 2013) não foram avaliados por não estarem disponíveis a esta pesquisadora no momento da realização deste trabalho.
} 
Editora do Brasil (BOHEMY, 2013), a terceira edição de Sociologia para o ensino médio, da Editora Saraiva (TOMAZI, 2013) e Sociologia em movimento, da editora Moderna (SILVA et al, 2013).

Levou-se em conta no momento da análise se o conceito de classe é apresentado no material (tanto no volume único quanto no manual do professor em anexo), como é apresentado, quais concepções teóricas e autores estão vinculados ao conceito e se há relação entre o conteúdo apresentado com a noção de classe proposta por E.P. Thompson, direta - citando o autor de alguma forma - ou indireta - apresentando aspectos que possam ser considerados conectados à proposta do autor. Além disso, considerou-se a avaliação de cada um dos livros presente no Guia de Livros Didáticos ${ }^{4}$ (Guia PNLD, 2014). Os resultados da análise estão dispostos através de um item para cada livro, e em seguida propôs-se um quadro com os principais aspectos de cada material.

\title{
3.1 Sociologia, da editora Scipione
}

O tema está disposto no primeiro capítulo do livro, no item "a sociologia se preocupa com a desigualdade social". O subitem chama-se "as teorias de classe e a estratificação social". O texto chama atenção para o fato de que "afirmar que a desigualdade faz parte da estrutura das sociedades não significa afirmar que ela é natural" (ARAÚJO et al, 2013, p. 16). A definição de classe dada é

\begin{abstract}
em linhas gerais, as classes sociais são grandes grupos que se diferenciam pelo poder econômico e político que possuem e pelo lugar que ocupam na produção e no consumo. A mobilidade de indivíduos, grupos e classes sociais pode se dar, por exemplo, devido à sua escolarização, participação política ou profissão. Porém, há outros fatores determinantes das desigualdades sociais, como as relações étnico-raciais e as de gênero. (ARAÚJO et al., 2013, p. 17).
\end{abstract}

Ao apresentar a desigualdade ao longo da história, explica-se que na sociedade capitalista o principal definidor da posição do indivíduo na estrutura social é a propriedade dos meios de produção (terra, fábrica, banco, equipamentos, etc.) e que essa

\footnotetext{
${ }^{4}$ A equipe responsável pela avaliação foi coordenada pela professora Ileizi L. F. Silva (UEL) e contou com 26 avaliadores. A instituição responsável pela avaliação foi a Universidade Federal do Paraná (UFPR).
} 
interpretação, de Karl Marx, está "assentada na noção de classes sociais como grandes interesses sociais agrupados e contrários um ao outro". (idem, p. 17)

Coloca-se ainda a divisão entre duas classes fundamentais (burgueses e trabalhadores) e que na sociedade capitalista a maioria dos indivíduos vende sua força de trabalho. A partir desse processo, o capital poderá ser sempre revertido em mais capital.

O livro apresenta em seguida a proposta de Max Weber e a estratificação social. E faz uma importante observação:

Tanto o tema das classes sociais quanto o da estratificação social são muito discutidos na literatura sociológica, por comportarem diferentes concepções de divisão da sociedade na civilização ocidental. [...] A posição de um indivíduo num sistema de estratificação é uma questão controversa. Inúmeras classificações da realidade social geralmente utilizada na mídia, como as que expressam as "classes sociais" em A, B, C, D, usam critérios simplificados para separar populações em grupos que nem sempre dizem respeito à experiência real que cada um tem na sociedade, nem à sensação de identidade e pertencimento de classe. (ARAÚJO et al, 2013, p. 18).

A seguir o material didático apresenta as diferenças entre a visão de Marx e Weber a respeito de classes e estratificação, e sintetiza em um quadro quatro teorias sobre classes sociais: as de Karl Marx (1975), Max Weber (1977), Erik Olin Wright ${ }^{5}$ e Pierre Bourdieu (1983). Faz o fechamento do tema com uma proposta de reflexão interessante:

No Brasil, neste início do século XXI, tem chamado a atenção dos cientistas sociais a emergência do que se denominou uma "nova classe social". Ou seja, um segmento da população obteve uma mobilidade social ascendente pela facilidade de acesso a bens de consumo e a novos hábitos sociais, marcando posição por seu poder aquisitivo. A indagação que se coloca é: será essa realmente uma "nova" classe social ou apenas um estrato social que se destaca no consumo de bens e serviços, sem que haja alteração na estrutura de classes e nas desigualdades da sociedade brasileira? (ARAÚJO et al, 2013, p. 20).

O livro e o manual do professor em anexo não fazem menção a E.P. Thompson, nem o sugerem como leitura complementar.

\subsection{Tempos modernos, tempos de sociologia, da Editora do Brasil}

\footnotetext{
${ }^{5}$ A obra de Erik Olin Wright de onde é retirado o conceito não é citado nas referências do livro analisado.
} 
O tema é apresentado no oitavo capítulo do livro, intitulado "trabalhadores, univos", em que é apresentado ${ }^{6}$ Karl Marx (e com menor destaque Jean-Jacques Rousseau e Friedrich Engels) e as noções de cooperação, propriedade privada e classes sociais. Ao tratar do subitem "as classes sociais", o texto segue a conceituação marxiana, enfatizando que apesar de a luta de classes marcar toda a história da humanidade, essas lutas diferem de acordo com os estágios históricos. (BOMENY et al, 2013, p. 119).

\begin{abstract}
São, portanto, as relações de propriedade que dão origem às diferentes classes sociais. Assim como não podemos escolher nossos pais, não podemos escolher nossa classe social. Esse pertencimento de classe está relacionado ao lugar que ocupamos na produção. Para Marx, a base da ordem social de todas as sociedades reside na produção de bens, na organização econômica. O que é produzido, como é produzido e como os bens são trocados é o que determina as diferenças de riqueza, de poder e de status social entre as pessoas. (BOMENY et al, 2013, p. 119, grifo das autoras).
\end{abstract}

No subitem seguinte ao de classes sociais, chamado "teoria e prática", o texto acena para a trajetória de luta e a repercussão de Marx e a partir daí apresenta a sua proposta de superação do capitalismo. Ao fim do subitem, afirma:

Sendo a única classe social que "já não tem nada a perder" e constituindo a maioria da sociedade, o proletariado tornara-se capaz de conduzir o processo de libertação de toda a humanidade. Para Marx, esse processo começaria com o socialismo em uma nação e se encerraria com o comunismo em todo o planeta. Daí sua participação na organização da Liga Comunista e Primeira Internacional, instituições políticas que ajudariam os trabalhadores de todo o mundo nessa jornada. (BOMENY et al, 2013, p. 121).

Após isso, o livro traz um box explicando o conceito de socialismo e encerra o capítulo com um trecho do Manifesto do Partido Comunista. A partir dessa análise, é um tanto questionável, mas importante registrar que o Guia de livros didáticos (Guia PNLD, 2014) traz uma ressalva ${ }^{7}$ na avaliação do livro em relação à forma como é tratada a noção de classe:

As discussões sobre desigualdades são completas na dimensão social, mas pouco significativas na dimensão econômico-social e na perspectiva marxiana de conflitos de classes no Brasil contemporâneo, que aparece em uma única menção através de uma fotografia. Assim, será importante na

\footnotetext{
${ }^{6} \mathrm{O}$ livro apresenta, dos capítulos cinco a doze, um autor consagrado da área a cada capítulo.

${ }^{7}$ Este é o único livro didático que sofre esse tipo de ressalva em relação à classe no Guia.
} 
discussão sobre as desigualdades no Brasil cuidar dessa questão dos conflitos de classes sociais, atualizando-as (Guia PNLD, 2014, p. 27).

Esta avaliação do Guia pode estar vinculada ao capítulo 18 - Desigualdades de várias ordens - na terceira parte do livro em que se trata especificamente do Brasil. Nesse capítulo, de fato, a noção de desigualdade é mais enfocada que a de classe, mas os estudantes já teriam um contato bastante significativo com a noção de classe no capítulo específico citado anteriormente.

E. P. Thompson é citado no primeiro capítulo (p.16), que trata das transformações da modernidade: um pequeno trecho de Costumes em comum, sobre como o tempo passa a ser moeda, está apresentado em um box. No entanto, o autor não está diretamente ligado à noção de classe apresentada no livro.

\subsection{Sociologia para o ensino médio, da editora Saraiva}

O livro traz a discussão sobre classes sociais em seu oitavo capítulo, "A sociedade capitalista e as classes sociais". Ao tratar da estratificação e mobilidade, o texto irá apresentar a proposta marxiana de que a desigualdade é constitutiva da sociedade capitalista, e se dá através da luta de classes. Coloca também que na sociedade capitalista está evidente que as relações e estruturas de apropriação econômica e dominação política definem a estratificação social (TOMAZI, 2013).

Para identificar as classes numa sociedade capitalista é necessário fazer uma análise da constituição histórica dessas classes e do modo como se enfrentaram politicamente, principalmente nos momentos mais decisivos. É nesse processo que aparecem e se desvendam as características e os interesses de classe, tanto das fundamentais quanto das intermediárias. (TOMAZI, 2013, p. 101).

A apresentação da perspectiva de Marx continua nos subitens "A luta de classes" e "A mais-valia", e ainda num box com trechos do autor. O olhar marxiano para o tema recebe o maior espaço na apresentação do capítulo, mas Max Weber também é apresentado no subitem "Desigualdades de riqueza, prestígio e poder" e em um box com trecho de sua obra. Os autores norte-americanos Kingsley Davis e Wilbert Moore (1979) são apresentados no subitem "oportunidades e estratificação" e têm parte de um texto exposto no box "a necessidade funcional da estratificação". 
E.P. Thompson é citado na página 55, em outro capítulo, sobre o trabalho, sobre a "santa segunda-feira" que ele discute em Costumes em comum (1998). Não há referência ao autor quando se trata da noção de classe, nem é proposto como leitura complementar.

\title{
3.4 Sociologia em movimento, da editora Moderna
}

O livro traz a noção de classe no capítulo 10, intitulado "estratificação e desigualdades sociais". O subitem "classes e desigualdades sociais" traz uma concepção de classe que se inicia com a proposta marxiana e posteriormente vincula a visão weberiana e é apresentado da seguinte forma:

\begin{abstract}
Uma característica do sistema de classes é a mobilidade social. De modo geral, existem dois tipos de mobilidadade social: quando a mudança de posição ocorre no sentido de subir ou desce na hierarquia, a mobilidade é vertical; quando se opera dentro da mesma "camada", há mobilidade social horizontal. A sociologia costuma privilegiar duas abordagens sobre as classes sociais, produzidas por Karl Marx e Max Weber. (SILVA et al, 2013, p. 238).
\end{abstract}

Mais à frente no capítulo, o texto apresenta uma relação entre os conceitos de distribuição de renda e classes sociais, juntamente a uma figura que apresenta a "distribuição da população de acordo com as classes sociais":

Devido a essa melhor distribuição de renda, a tradicional divisão de classes sociais em A,B,C,D e E sofreu um rearranjo, pois a estrutura passou de uma forma piramidal para outra do tipo losango, que mostra um expressivo crescimento da classe denominada $\mathrm{C}$, com redução quantitativa das classes $\mathrm{D}$ e E. Essa mudança estaria se efetivando em decorrência de programas sociais, como o Bolsa Família e da melhoria da remuneração de uma "nova classe média" [...] (SILVA et al, 2013, p. 245).

Em seguida, o livro expõe um box em que se apresenta esse conceito de "nova classe média" e o debate que há sobre ele entre os especialistas da área. E.P. Thompson não é citado no livro.

\section{Considerações finais}


A leitura dos livros de sociologia para o ensino médio leva a crer que a inserção da obra de E. P. Thompson entre cientistas sociais brasileiros, descrita, por exemplo, por Mattos (2006), ainda não encontra uma extensão significativa entre a produção de material didático da disciplina. O autor é citado em dois dos livros analisados (TOMAZI, 2013; BOMENY, 2013), mas a atenção dada à sua obra é ínfima, e não está relacionada à sua noção de classe, tão cara às ciências sociais.

Em todos os livros, a clássica concepção de classe de Karl Marx aparece, tendo maior ou menor ênfase no conjunto de apresentações sobre classe. Tomazi (2013) e Bomeny et al (2013) parecem tratar mais fortemente da noção de classe sobre o viés marxiano; Araújo et al (2013) um pouco menos, mas traz uma reflexão importante sobre a forma equivocada como classe social vem sendo tratada como capacidade de consumo.

Além disso, os aspectos simbólicos e culturais, e a ênfase na dominação, muito presentes na noção de classe thompsoniana, acabaram tendo pouco destaque provavelmente a exceção esteja em Tomazi (2013), que atenta à construção histórica da classe e dos conflitos das relações de classe de forma mais evidente. Apesar de Thompson não estar diretamente citado nos capítulos que trataram de classe em nenhum dos livros analisados, se quisermos fazer um esforço na busca por sua influência, é possível lembrar que dois livros, Tomazi (2013) e Silva et al (2013), citam Sader (1988) que utilizou da noção de classe de Thompson em sua reflexão sobre os novos movimentos sociais dos anos 1970 - ainda que recebendo críticas de Mattos (2006, p.89) por ter realizado "referências cruzadas" - como Foucault e Castoriadis) que não encontrariam respaldo nos textos de Thompson.

Talvez os casos que se afastem mais da noção de classe de Thompson seja a citação em Tomazi (2013) da visão funcionalista através de Davis e Moore - tão criticada por Thompson - sem uma posterior proposta de crítica ou embate das teorias. Além disso, o livro da editora Moderna (SILVA et al, 2013) apresentou uma noção de classe mais suavizada, sem ênfase nos conflitos ou dominações, e apresentando uma relação bastante simplista entre classe e consumo.

De qualquer forma, a consolidação da presença da sociologia no ensino médio brasileiro é recente e permeada por uma série de dificuldades inerentes a um processo que ainda se encontra em construção. Dentre as dificuldades, há os aspectos ligados 
especificamente aos conteúdos e materiais didáticos, como já mostrou Moraes (2003). Ainda que seu trabalho relate alguns aspectos que já foram superados, o autor defende que para os materiais didáticos de sociologia obtenham mais qualidade, é importante que haja duas iniciativas:

\footnotetext{
Reconhecimento pela comunidade de cientistas sociais de uma área de pesquisa em Ensino de Sociologia, com espaço para debates e divulgação de pesquisas nos seus fóruns e para a publicação em sua imprensa periódica. Superação do modelo atual de formação do professor de sociologia, com integração efetiva entre bacharelado e licenciatura (MORAES, 2003, p. 13).
}

Aqui, vale retomar também algumas palavras de Lajolo (1996, p. 12):

\begin{abstract}
No processo de seleção do livro didático e ao longo de sua presença na sala de aula, é preciso planejar seu uso em relação aos conteúdos e comportamentos com que ele trabalha. É só a partir disso que se pode descobrir a melhor forma de estabelecer o necessário diálogo entre o que diz o livro e o que pensam os alunos. Pois é só na interação entre o saber que se traz do mundo e o saber trazido pelos livros que o conhecimento avança.
\end{abstract}

Como se vê, independente do livro didático escolhido pelo/a professor/a, é fundamental que este/a tenha o cuidado de problematizar o material que tem em mãos e oferecer aos estudantes possibilidades complementares de conhecerem outros autores e propostas teóricas.

\title{
Referências
}

ARAÚJO, S. M; BRIDI, M. A.; MOTIM, B. L. Sociologia. São Paulo: Scipione, 2013.

BOURDIEU, P. Questões de Sociologia. Rio de Janeiro: Marco Zero, 1983.

BRASIL. Guia de livros didáticos: PNLD 2015: sociologia: ensino médio. Brasília, Ministério da Educação, Secretaria da Educação Básica, 2014.

DAVIS, K; MOORE, W. Alguns princípios de estratificação. In: BERTELLI, A.R et al (orgs.). Estrutura de classes e estratificação social. Rio de Janeiro: Zahar, 1979.

FREIRE-MEDEIROS, B. et al.Tempos modernos, tempos de sociologia. BOMENY, H. (coord.), 2a ed. São Paulo: Editora do Brasil, 2013. 
LAJOLO, M. Livro didático: um (quase) manual de usuário. Brasília: Em aberto, ano 16, n.69, 1996.

MACHADO, I. J. R; AMORIM, Henrique; BARROS, Celso R. Sociologia hoje. São Paulo: Ática, 2013.

MARX, K. O Capital. 3ª ed. Rio de Janeiro: Civilização Brasileira, 1975.

MATTOS, M. B. EP Thompson no Brasil. Outubro. Revista do Instituto de Estudos Socialistas [online], n. 14, 2006.

MORAES, A. C. Licenciatura em ciências sociais e ensino de sociologia: entre o balanço e o relato. São Paulo: Tempo social, v. 15, n. 1, 2003, p. 5-20 .

MORAES, M. C; MÜlleR, R. G. E. P. Thompson: e a Pesquisa em Ciências Sociais. In: MÜlleR, R. G; DUARTE, A. (orgs.). E. P. Thompson: política e paixão. Chapecó: Argos/Unochapecó, 2012, p. 281-325.

OLIVEIRA, L. F.; COSTA, R. C. R. Sociologia para jovens do século XXI. $3^{\text {a }}$ Ed. Rio de Janeiro: Imperial Novo Milênio, 2013.

RHOMBERG, C. Clase y acción colectiva: escribir historias sobre actores y eventos. Sociología Histórica [online], n. 3, 2013, p. 117-143.

SADER, E. Quando novos personagens entram em cena. Rio de Janeiro: Paz e Terra, 1988.

SILVA, A. et al. Sociologia em movimento. $1^{\text {a }}$ ed. São Paulo: Moderna, 2013.

THOMPSON, E. P. Costumes em comum: estudos sobre a cultura popular tradicional. São Paulo: Companhia das Letras, 1998.

A formação da classe operária inglesa. I - A árvore da liberdade. $4^{\mathrm{a}}$ ed. Rio de Janeiro: Paz e Terra, 2004.

TOMAZI, N. D.. Sociologia para o ensino médio. 3ª ed. São Paulo: Saraiva, 2013.

WEBER, M. Economia y sociedad. v.1. Bogotá: Fondo de Cultura Económica, 1977.

WOOD, E. M. Democracia contra Capitalismo. São Paulo: Boitempo, 2002. 


\title{
O conceito de classe: os livros didáticos de sociologia e a proposta de E.P. Thompson
}

Resumo: O trabalho propõe uma análise dos novos livros didáticos de sociologia disponibilizados pelo Ministério da Educação a partir do Programa Nacional do Livro Didático (PNLD) em 2014, com enfoque específico na forma como a noção de classe é tratada em cada um dos materiais em questão. Partindo da noção de classe defendida pelo historiador britânico E.P.Thompson, observam-se avanços na qualidade teóricoconceitual dos livros disponibilizados pelo programa, mas ainda um distanciamento da proposta thompsoniana, que enxerga classe não como um conceito estanque, mas como relação que se dá como processo ativo e histórico.

Palavras-chave: Ensino de Sociologia; Livros didáticos; Classe

The concept of class: the sociology school books and the proposal of $E$. P. Thompson

\begin{abstract}
The paper proposes an analysis of new textbooks of sociology made available by the Ministry of Education from the National Textbook Program ( PNLD ) in 2014 , with specific focus on how the notion of class is treated in each of the materials in question. Starting from the notion of class advocated by British historian E.P. Thompson, we observe advances in theoretical and conceptual quality of the books provided by the program, but still a distance from the thompsonian proposal, which sees class does not like a tight concept, but as a relationship that takes place as active and historical process.
\end{abstract}

Keywords: Sociology teaching; Textbooks; Class 
Recebido em: 07 de junho de 2015.

Aceito para publicação em: 24 de julho de 2015. 